\title{
Girls that wear Abercrombie \& Fitch: Reading fashion branding aesthetics into music videos
}

\author{
Myles Ethan Lascity, Southern Methodist University \\ mlascity@smu.edu
}

\begin{abstract}
Teen clothier Abercrombie \& Fitch's mix of shirtless associates, nightclub-like stores and risqué photography by Bruce Weber helped propel the brand into icon status. The brand's name entered the popular lexicon as a synonym for cool and even received a memorable call out in LFO's pop song, "Summer Girls." This paper explores the interplay in aesthetics between A\&FQuarterly, the brand's popular magazine-catalog hybrid, and popular music videos of the time. Specifically, this paper analyzes videos that appeared on MTV's Total Request Live between September 1999 and April 2001. In total, 42 music videos were found to contain elements of the "Abercrombie" lifestyle, including clothing that was sold by the brand, and props and settings similar to those found in the A\&F Quarterly. In sum, this suggests that music videos from the time were instrumental in spreading the brand's aesthetic, and that the interplay between media popular culture and the aesthetics of fashion brands could yield productive future research.
\end{abstract}

Keywords

fashion branding, fashion communication, music videos, mediated popular culture

\section{Introduction}

Music videos have been a staple of popular culture since the launch of MTV in the early 1980s, but, their popularity and influence waxed and waned over the years (Arnold, Cookney, Fairclough \& Goddard, 2017; Middleton \& Beebe, 2007). Starting in September 1998, music videos regained prominence with the launch of Total Request Live - TRL for short - from its studios overlooking Times Square in New York City. Screaming fans lined Broadway, interacting street side with hosts and waving and flashing signs toward in-studio host Carson Daly. The show was a mixture of music videos, musical guests and friendly banter. During its run TRL helped launched a slew of pop stars, including 'N Sync, the Backstreet Boys, Brittany Spears, Christina Aguilera, 98 Degrees, Jessica Simpson and Mandy Moore. As marketing turned to "cool as hunters" to catch teen trends, little was an influential as TRL (Dretzin \& Goodman, 2001).

At the same time, a teen fashion behemoth was being developed in the form of Abercrombie \& Fitch. The fabled retailer that once outfitted the likes of Teddy Roosevelt and Ernest Hemingway had turned its attention to teens in 1992 and never looked back. With CEO Mike Jeffries at the helm, the store became a mall phenomenon, selling an aspirational lifestyle to teens through jeans, T-shirts and flip flops. The chain was not without its detractors: parents saw Abercrombie's racy photos as sexualizing youth while the company's hiring and employment practices were thought to be exclusionary and racist. Still, the company had remarkable growth financial growth and cultural influence.

The worlds of TRL and Abercrombie collided with the 1999 release of LFO's "Summer Girls." The song became the group's first (and biggest) hit, but also became a major "song of the summer." Most importantly, the lyrics name dropped Abercrombie \& Fitch in its refrain giving the store a boost of publicity. The connection between the song and the band was so extensive that when the retailer ran into trouble in 2016, CNN Money used the headline "Summer girls no longer shop at Abercrombie and Fitch" (La Monica, 2016). In addition to several mentions of 
brand, the video looked like something that could have been ripped from Abercrombie's marketing materials. However, "Summer Girls" was hardly the only video promoting such a lifestyle; videos across the TRL spectrum including from artists like Britney Spears, Christina Aguilera and 98 Degrees also reflected the Abercrombie style.

This paper is a historical analysis that seeks to highlight the similarities of popular music videos that appeared on the U.S. version of $T R L$ and the imagery presentation in Abercrombie \& Fitch's marketing. By examining similarities in aesthetics, props, settings and characters, it is possible to see how the same imagery and lifestyle that was drawn on for LFO's "Summer Girls" was reflected in other music videos as well. This understanding of intertextuality within popular culture (Fiske, 2011, pp. 98-101) has been shown in other collections of music videos (De Cuir, 2017; Halligan, 2017) and suggests forms and aesthetics can influence one another. Taking this one step further, this paper traces the influence of Abercrombie \& Fitch imagery through music videos between 1998 and 2001 and suggests that the brand was part of the cultural zeitgeist at the turn of the millennium largely due to its outsized influence within these music videos.

\section{Music videos to TRL}

While music videos gained prominence with the launch of MTV in 1981, their roots can be traced back decades earlier. As Rich (2008) points out animated videos such as Looney Tunes and Merrie Melodies merged visual art forms with music as early as the 1920s (p. 79). By the 1950s, musicians were making appearances in films and TV shows to promote their music - a process that reached a fever pitch with the fictional rock band the Monkees (Rich, 2008, p. 80). Once launched, MTV's popularity rose through 1984 before seeing a sharp decline in 1985 due to copycat channels (Aurfderheid, 1983, p. 61). Ultimately, MTV continued to grow and reached more than 52 million households by 1990, and was competing with the likes of CMT, BET and VH-1 (Rich, 2008, p. 81).

Given their popularity, music videos have long been sites of research and theorization (Arnold et al., 2017; Aurfderheid, 1983; Beebe \& Middleton, 2007; Frith, Goodwin, \& Grossberg, 1993; Sun \& Lull, 1983; Railton \& Watson, 2011; Vernallis, 2004). Generally, the creation of music videos is understood as a postmodern undertaking due to its fractured storytelling and hyper-reality (Straw, 1993, p. 12), but debate continues over the qualitative differences between music videos and other media. Vernallis suggests that music videos are a wholly different media form: they take parts from film and television, but should not be understood in through the same mechanisms researchers and theorists have used for other cultural products (Vernallis, 2004, p. 3). Music videos "are different from its predecessors - film, television, photography - a medium with its own ways of organizing materials, exploring themes and dealt with time" (Vernallis, 2004 , p. x). Vernallis notes that music videos come from the songs they are created for, but meanings come from the "giveand-take" of sound and image (Vernallis, 2004, p. x). Like other forms of media, music videos relay on a mixture of narrative, video editing, characters, settings, props and sound for its creation (Vernallis, 2004, p. xi-xiii).

Some recent discussions of the "music video turn," as Arnold et al. (2017, p. 5) call it, have focused on how digital platforms like YouTube have altered creation and consumption of videos (Cookney, 2017; Manghani, 2017). This changing of context brings with it a renewed need for theorization, and can help shed light on previous discussions and times. Both earlier formats like the jukebox film (Herzog, 2007) and contemporary forms of digital videos have helped to separate the MTV channel from the music video programming which made it successful (Middleton \& Beebe, 2007). Of note for this discussion, is how the channel and context on of music videos can mold its influence and consumption. Shows like The Ed Sullivan Show and American Bandstand were able to influ- 
ence music consumption and highlight particular artists and broadcasting conventions (Coates, 2007). The same can be said for TRL.

While game shows, comedies and reality shows became more prominent on MTV through the 1990s, TRL's debut in 1998 brought music videos back to the spotlight. According to MTV, the show "was one of the first truly interactive television shows, utilizing the synergy of the internet and television to countdown the top music videos of the day" (MTV, n.d.). The show aired in the afternoon-at 3 p.m. in the summer and 3:30 p.m. during the school year-and boasted ratings $52 \%$ among 12-to-34-year-olds in its first quarter (Heller, 2000). TRL's peak popularity occurred in 1999 and 2000 when the show averaged more than 700,000 viewers. MTV finally pulled the plug on the show in 2008 after falling ratings and increase competition from the Internet (Sisario, 2008).

Following arguments that the medium context is important for understanding consumption (Cookney, 2017; Herzog, 2007; Middleton \& Beebe 2007; Kooijman, 2017; Manghani, 2017), it must also be acknowledged that specific shows and influence consumption. TRL not only influenced what videos were watched, but helped package them into a program for consumption. Carson Daly and the rest of the TRL's hosts used friendly banter, celebrity interviews and fan interaction to create a whole show and thereby helping link the videos together.

\section{Fashion and storytelling in music videos}

As noted above, music videos have a unique way of dealing with a host of storytelling dimensions, including costume and, as such, fashion. Various works interrogate fashion as part of film (Gaines, 2000; Munich, 2011; Uhlirova, 2013), television (Bruzzi \& Church Gibson, 2004; Warner, 2014) and even music (Miller, 2011), but the relationship between fashion and music video has not received as much sustained attention. This may be due to music videos' place as the "Kleenexes of popular culture" (Railton \& Watson, 2011, p. 1), but also due to researchers more sustained interested in representation and embodiment (Arnold etal., 2017, pp. 91-139; Lewis, 1993; Mercer, 1993; Railton \& Watson, 2011; Vernallis, 2004, pp. 209-235; Wasler, 1993).

Still, as Miller points out, “... both music and fashion marketing are fed by a variety of practical and visual interrelationships in which fashion are style are core to a kind of intertextual taste-sharing between the two industries" (2011, p. 12). Vernallis notes that music videos allow even more of an emphasis on costume and clothing, however, she glosses over the clothing and emphasizes the symbolic nature of the garments (2004, pp. 100-104). There's no reason to believe that this symbolism cannot flow in different directions, especially since the concept of fashion branding emphasizes the cultural context surrounding garments (Hancock, 2009a, pp. 4-5). Miller highlights the intertextual relationship between music videos and particular garments in her analysis of Gwen Stefani's "Rich Girl." The video drew heavily from the fashion advertisements of John Galliano and Vivienne Westwood, and, through the presence of Stefani, promoted her own fashion line, L.A.M.B. The connections helped to establish the singer as a taster arbiter and L.A.M.B. as a peer of Galliano and Westwood (Miller, 2010, pp. 24-25). This is an example of intertextuality where the fragmented elements of fashion branding and fragmented storytelling of music videos overlaps to influence both products.

\section{Methods}

Acknowledging the intertextuality within videos, it is possible to imagine how the brand image of Abercrombie \& Fitch could get tied up with popular music videos at the height of its popularity. Notable for this analysis is the mention of Abercrombie \& Fitch in the LFO song, "Summer Girls." Assuming that sight and sound does intertwine in this video (Dickinson, 2007), it can be presumed the reference had a clear 
influence on the brand's image. Further if, as De Cuir (2017) has noted, aesthetics and ideology from one video can influence others, and if repeated imagery across music videos can create particular consumption lifestyles (Halligan, 2017), then it is possible to see elements from "Summer Girls" reflected throughout the music landscape.

As such, the following pages are a close reading of popular music videos from the turn of the millennium that link their aesthetic qualities with Abercrombie \& Fitch's brand image. This paper first sets out Abercrombie \& Fitch's brand image as theorized by researchers and the popular press during this time period before conducting three different analyses to explore the pervasiveness of the brand image within music videos. First, the Abercrombie \& Fitch image is explored within the "Summer Girls" video, as it directly mentioned the brand. Then, two different analyses are made with other popular music videos of the time. First, individual music videos are analyzed for similar themes of the brand's marketing; then, specific elements of the brand - both clothing and settings - are explored in various music videos. These videos selected and used within the analysis appeared on TRL between Sept. 1998 and April 2001, according to an unofficial database kept on atrl (atrl, n. d.), and were analyzed in October 2016. In total, there were 42 songs that appeared on the countdown fit some elements of the Abercrombie aesthetic, whether through settings, props or costuming. The videos detailed below were chosen because they offer the most salient examples of this interplay.

\section{Abercrombie \& Fitch style}

At the same time that MTV was enjoying increased prominence due to TRL's success, Abercrombie \& Fitch was in the midst of its own renaissance. The storied sporting goods retailer had been revived as a clothing brand by The Limited in 1988 (The New York Times, January 16, 1988). In 1992, The Limited installed Mike Jeffries as Abercrombie \& Fitch's CEO and under his leadership the brand flourished. In 1997, Abercrombie \& Fitch launched its magazine-catalog hybrid (also known as a magalog), A\&F Quarterly, which featured the erotic photography of Bruce Weber along with a variety of written articles and features.

$A \& F$ Quarterly buttressed the company's experiential branding efforts, which included darkening the sales floor, playing music at club levels and employing good looking young people in their stores (Goldstein, 2000). As Hancock (2009b) notes, Abercrombie was successful at selling a hypermasculinized image through its use of homoeroticism and sex scenes (pp. 6971). In store, this included the employment of shirtless, male greeters accompanied by female assistants to blunt overt homosexual tones (Hancock, 2009a, p. 100). While the greeters brought Weber's imagery to life, the magalog went further to create what journalist Stacy Perman called, a "Technicolor teen lifestyle" (2000).

And, truly, A\&F Quarterly offered advice for every facet of life. Being released quarterly, the magalog updated this lifestyle for Spring Break, Summer, Back-toSchool and Christmas. Among the articles offered by in the magalog, readers could get drink recipes, sex tips, travel advice, celebrity interviews and even philosophical discussions. While many brands attempt to sell a "lifestyle," (Saviolo \& Marazza, 2013, pp. 48-49). Abercrombie \& Fitch marketed a completely fictional, yet highly desirable, lifestyle through its marketing communications in a manner that had not be matched. Under Jeffries, Abercrombie's profits increased for a decade and only fell after the 2001 recession, during which the CEO bucked conventional wisdom and refused to lower prices. While there would be some positive turns in the years after, the 2008 recession also took a toll, although it would take until 2014 for Jeffries to be replaced and the brand to attempt to change course (Berfield \& Rupp, 2015).

Still, it cannot be ignored that Abercrombie's success came largely through exclusion and the erasure or mocking of racial minorities, overweight teens or anyone else deemed "uncool." As Jeffries 
made clear in a 2006 interview, the brand aimed specifically for the cool kids and others need not apply. Jeffries said, "In every school there are the cool and the popular kids, and then there are the not-so-cool kids. Candidly, we go after the cool kids. We go after the attractive all-American kid with a great attitude and a lot of friends. A lot of people don't belong [in our clothing], and they can't belong. Are we exclusionary? Absolutely" (as qtd. in Denizet-Lewis, 2006). This lead to a discrimination lawsuit by Asian American, African American and Latino teens in 2003 that the company settled for $\$ 50$ million (Berfield \& Rupp, 2015); a religious discrimination suit in 2008 (Liptak, 2015) and numerous boycotts. McBride (2005) laid out his criticism of the brand in the book "Why I Hate Abercrombie \& Fitch," where he documented how the brand's promotional images and control over store employees worked to promote and reinforce a primarily white, male image (pp. 66-83). Reinforcing a more racist exclusionary practice, one former associate told McBride, "that African American and Asian Americans 'can be $\mathrm{A} \& \mathrm{~F}$ if they act white, have white friends, and are very assimilated'” (p. 82).

\section{Girls that wear Abercrombie \& Fitch}

Abercrombie \& Fitch truly entered the popular culture landscape with 1999's ubiquitous song of the summer, LFO's "Summer Girls." The song was released on the band's self-titled debut album and peaked at number 3 on the Billboard Hot 100 chart (“Summer Girls," LFO, n.d.). The album later peaked at number 21 on the Billboard 200 (LFO, LFO, n.d.). LFO followed up with several singles and a follow-up album in 2001 without the same success. "Summer Girls” remains LFO's defining song and has been ranked as one of the best "summer songs" by Billboard (Billboard Staff, 2014) and one of the best songs released by a boy band (Benjamin et al., 2015).

The song was well known for its referential lyrics and refrain that included the line "I like girls that wear Abercrombie and Fitch" and later reference that states, "You look like a girl from Abercrombie and Fitch." The lyrics do not explain what exactly that means, but taken in tandem with the video we can start to parse out some conclusions. More importantly, there is an overlap in imagery between the "Summer Girls" video (Raboy, 1999) and the advertisements in the A\&F Quarterly. By teasing out the narrative, characters, settings and props within the video it is possible to see the "Summer Girls" video as a reflection of the Abercrombie \& Fitch aesthetic.

From the start of "Summer Girls," there is a group of good looking young women arriving at a beach house in an classic black convertible, where the members of LFO are anticipating them. Three young, thin, attractive and white women clad in swim suits and other midriff-bearing outfits climb out of the car and meet the band members on the porch. The group members, who are also young, attractive and white, are dressed in more conservative attire, namely various forms of cargo or khaki pants, and T-shirt shirts and a sweater. The excitement is obvious and the women eagerly hug and jump on men.

The video then transitions into its second setting, a boardwalk scene. The video returns to this scene through and at times the group is singing while sitting on a picnic table or standing on top of the boardwalk stalls. At various points, a group of primarily young women - again, thin, attractive, white and dressed in somewhat revealing clothing - huddle around the group. At other points, the entire group of characters walks along with boardwalk in various states of physical engagements holding hands, arms wrapped around each other and gesturing suggestively. At one point, the group watches a series of break dancers, who are also the most notable men outside of the band in the video.

Scenes are spliced between the boardwalk scene and the beach house scene, the latter of which has also become overrun with young adults dancing and having fun around the classic car. The dancing becomes more excited as the song goes on and eventually moves to include the group dancing and playing at the ocean's edge. 
Here, the young adults are dancing as the waves roll in around them, soaking their pants and skirts; they are unmoved though because they are having too much fun. As day turns into night, the beachgoers huddle in towels and hooded sweatshirts while they sit away from the water. The scene is brief, however, as the video cuts back to the boardwalk scene from earlier.

There are several points to note here as several of the props used in the video line up closely with items that were sold in the A\&F Quarterly around the time of the video's release. First, there is a young woman in the boardwalk scenes wearing a green camisole top with a pair of short orange cargo shorts. Similar shorts can be found for sale in A\&F Quarterly (2000b, p. 42). A second comparison can be made between LFO member Devin Lima (2000b), who is wearing a pair of zip-off cargo pants, similar to those sold by the brand (p. 12). Finally, there is a young women of ambiguous heritage, who is wearing a yellow, ribbed tank top and a patterned skirt. Both of these garments are similar to things sold in Abercrombie's magalog (A\&F Quarterly 2000b, pp. 33; 55).

Further, these characters are similar to the Abercrombie aesthetic. As mentioned above, the brand aimed heavily for the "cool, good-looking people" (Denizet-Lewis, 2006) at the expense of anyone not fitting into that mold. The video showed much the same. There is no one who does not fit tradition stereotypes of attractiveness; the young women are thin and the young men are muscular. Further, and perhaps most notably, most of the young adults are white. There are few racial or ethnic minorities portrayed in the video - the young women of ambiguous ethnicity being the most prominent. One of the break dancers appears to the black, and there appears to be one or two other people of color in the crowd-however, they are primarily in the background and play no extended role in the video. It is notable that Abercrombie had been sued for racial discrimination (Berfield \& Rupp, 2015) and that journalists have documented that "less cool and less good-looking" workers did the inventory and replace- ment work in the store afterhours, after those hire to have a "good time" went home (Goldstein, 1999). A similar situation exists in the video where everyone is good-looking - those that do not measure up are simply erased in "Summer Girls" and minorities take a backseat.

Having fun is also the primary activity and narrative in the video. Essentially, "Summer Girls" has little other action beyond singing and having fun - whether at the beach house, on the boardwalk or on the beach. This is similar to the $A \& F$ Quarterly, where young adults live a life of relative leisure, and Abercrombie \& Fitch's employees who work as a "status thing" (Goldstein, 1999).

Finally, the settings also tie into the A\&F Quarterly. Similar beach scenes can be found throughout the magalog's run. For Spring Break 1999, the cover featured a models holding a surfboard overhead while standing on a beach. Further, many of the photospreads took place on or near beaches, and several articles dealt with surfing (Abadsidis, 1999; Bixby, 1999), beach life (Gillies, 1999) or travel to beach locales (Branch, 1999). These themes were repeated in A\&F Quarterly's summer 1999 edition titled, Summer Dreams. The cover was in black-and-white and featured a model on a tropical beach. Sand, palm trees and sand all featured prominently in photospreads and articles featured the difference between the beach and the pool (Kon, 1999) and featured pieces about beaches in Thailand (Carone, 1999).

\section{Beyond "Summer Girls"}

Seeing how the Abercrombie lifestyle played out in "Summer Girls," this section focuses on two other videos that highlight the intersection of these elements: Christina Aguilera's "Genie in a Bottle" and 'N Sync's "Merry Christmas, Happy Holidays." Both videos display various parts of the Abercrombie lifestyle, including beach scenes and holiday scenes, respectively.

"Genie in a Bottle" - Aguilera's debut single, "Genie in a Bottle," launched her career. The song reached number 1 on the 
Billboard Hot 100 in July 1999 ( "Genie in a Bottle," Christina Aguilera, n.d.), while the album, Christina Aguilera, reached number 1 on the Billboard 200 (Christina Aguilera, Christina Aguilera, n. d.). "Genie" was a staple of $T R L$, being "retired" after appearing on the countdown for 65 days (atrl, n.d.).

The video (Martel, 1999) resembles many of the elements of "Summer Girls" and the imagery sold by Abercrombie \& Fitch. The video begins with shots of Aguilera on a laying on a shady beach dune and her walking through a beach house and singing on a deck overlooking the shore. The scenes are shot in low light, making it difficult to determine a time of day, but also work to make the entire video more dream-like or mystical. As the video progresses, Aguilera is called by her friends to meet a group of guys who just arrived at the house - one of which is her love interest. Eventually, the entire group relocates to the beach for a bonfire and this scene is spliced with a scene where Aguilera performs a choreographed dance on a sandy dancefloor. The scenes throughout reflect the scenery of "Summer Girls" and of $A \& F$ Quarterly's beach scenes.

Again, the props refer back to the Abercrombie \& Fitch lifestyle. Specifically, during the choreographed dance Aguilera is wearing a pair of Abercrombie \& Fitch's orange drawstring pants as sold in the $A \& F$ Quarterly (1999, Spring Break, p. 49). The supporting characters are also clad in the Abercrombie \& Fitch aesthetic - from cargo shorts to Hawaiian print board shorts. In other props, the older convertible driven by the cohort of guys reflects the convertible as seen in "Summer Girls" and the style of car highlighted in the A\&F Quarterly (2002a, pp. 114-123).

Like "Summer Girls," all of the characters in "Genie" are young, attractive and primarily white. A key difference here is that many of Aguilera's backup dancers are people of color, but just as minority Abercrombie \& Fitch associates played a supporting role, all of the main characters are white. Despite being half Ecuadorian, Aguilera appeared as a pale women with blonde hair and can also be read as white.
The narrative in "Genie" also reflects a frivolity: the main narrative is around a nighttime beach party. Involved in the storyline is Aguilera's filtrations with one of the young men, but still this references the playfulness of "Summer Girls" and the Abercrombie lifestyle. This flirtation was key to Abercrombie's branding (Hancock, 2009a, p. 92-102) and also apparent in "Summer Girls."

Merry Christmas, Happy Holidays Unlike the successes of "Summer Girls" and "Genie," 'N Sync's "Merry Christmas, Happy Holidays" was more muted. In fact, the song did not chart on the Billboard Hot 100 and the group's Christmas album, "Home for Christmas" peaked at a 153 on the Billboard 200 (Home for Christmas, 'N Sync, n.d.). The song, however, has become a something of a holiday staple remaining on the Billboard Holiday chart and being covered by the Pentatonix nearly 20 years after its release (Spera, 2016). On TRL, the video appeared on the countdown daily between Dec. 14 and Dec. 22, 1998, reaching No. 1 three times.

The video (Martin, 1998) featured actor Gary Coleman as an elf tasked with replacing a Santa too sick to deliver presents. Finding an 'N Sync poster, he decides to call on the boy band to take over. The main scene is of the band members inside a sled in front of a green screen displaying scenes of the sky, the New York City skyline and other places the group is "traveling." The scenes are interspersed with other festive scenes: one scene shows the group feeding homeless people, another includes a Christmas-party like scene where people are dancing and decorating a tree, and still another shows band members giving gifts to their "loved" ones or likely girlfriends.

Unlike "Genie in a Bottle" and "Summer Girls," these scenes represent a different aspect of the Abercrombie lifestyle: the holiday season. "Christmas" was one of the four quarterly issues put out by the $A \& F$ Quarterly and like the other videos there appears to be a crossover in aesthetic and costuming.

In the video, band members are dressed for winter in fleece, vests and hooded sweaters. Justin Timberlake is wearing an 
orange fleece; JC Chasez is wearing a grey fleece and black fleece vest; Lance Bass is wearing a yellow hooded sweatshirt and grey puff vest; and Chris Kirkpatrick is wearing a red puff jacket. Joey Fatone is the odd man out wearing a T-shirt, but he is wearing a pair of cargo ski overalls, similar to the parachute and cargo pants the other members are wearing. Taken together these outfits reflect the style of Abercrombie at the time (A\&F Quarterly, 1998a, pp. 108-113), especially the fleeces garments (A\&F Quarterly, 1998a, p. 87; 1998b, pp. 95, 243)

Like the previous videos, "Merry Christmas, Happy Holidays" maintains a primarily young, attractive and white cast. The band members are all white as are many of the "party guests." It's notable that the "homeless" individuals 'N Sync are helping are primarily old and less conventionally attractive than the group and one of the homeless individuals is black. There are few other minorities throughout. There are two children of ambiguous race shown throughout, two attractive women - one black and one Asian - dance with Chasez and Timberlake, respectively, and Coleman appears as a comic elf. As such, the aesthetic reinforcing the Abercrombie style by again highlighting and centering the conventionally attractive, white individuals and marginalizing minorities.

Moreover, the feeling of the video is happy and celebratory, much like that of "Summer Girls" and "Genie in a Bottle." While "Merry Christmas, Happy Holidays" is more realistic in featuring needy individuals, the focus is certainly on the happy-go-lucky Christmas party and the joy in material giving (even to the needy). Further, it reinforces the stereotypes where the attractive, affluent youths can "save Christmas" and give to the poor while looking good and having fun.

\section{And the beat goes on}

As shown, this can be done with individual videos to see the lifestyles and aesthetics displayed throughout. However, repetition of objects, images and settings provide an important intertextual connection between disparate videos - with their own directors, artists and influences - into something more intelligible and influential. This repetition shows that the Abercrombie's influence was not concentrated in a few videos, but rather widely dispersed throughout videos seen on TRL. The next pages look at specific elements that were repeated in different videos of the time.

Clothing makes an obvious starting point since it was the more prominent product for Abercrombie. Two particular examples can be cited here: the camisole tops are sold two editions of the maga$\log (2000$ a, p. $76 ; 2000$ b, p. 15). Sold in a variety of colors, the shirts had spaghetti straps and made appearances across the music videos of the time. Musicians such as Britney Spears and Hoku wore the shirts in "Sometimes" and "Another Dumb Blonde," respectively, while they also made appearances in Jennifer Paige's "Crush," Backstreet Boys' "As Long As You Love Me," Mandy Moore's “Candy," Soul Decision's "Faded" and Vitamin C's "Graduation (Friends Forever)."

Similarities can also be found with men's ribbed, turtlenecks and sweaters and sold by Abercrombie \& Fitch (2000d, pp. 46-47). These sweaters made appearances on Nick Lachey in 98 Degrees' "This Gift," Jordan Knight in the "Give It to You" video, and in Britney Spears' "From the Bottom of My Broken Heart." Meanwhile, videos like 98 Degree's "Because of You," 'N Sync's "Music of My Heart" and "I Drive Myself Crazy," and Mariah Carey's "Thank God I Found You," all featured ribbed sweaters without the turtleneck - a similar style also available in the magalog.

Beyond clothing, other props were repeated throughout, including classic cars, old style microphones and surf boards. People were seen driving classic convertibles in Paige's "Crush," LFO's "Summer Girls" and "Girl on TV," Aguilera's "Genie in a Bottle," Shawn Mullins' "Lullaby," and O-Town's "All or Nothing," while various classic cars were also seen in Hoku's "Another Dumb Blonde," Jennifer Love Hewitt's "How Do I Deal," and Backstreet Boys' "As Long as You Love 
Me." Classic cars makes appearances in the Spring Break issue of 1999 (pp. 224, 227, 272, 295); the Back-to-School 1998 edition was dedicated to road trips as was the photospread "On the 101," (2002a, pp. 114-123), both featuring classic cars. Old cars were not the only crossover vehicles. In the Back-to-School 1998 issue, the magalog featured a late model Volkswagen Beetle (A\&F Quarterly, 1998a, pp. 14-15) similar to the one featured in Moore's "Candy." Meanwhile, a Jeep was gifted in the Christmas 2000 edition (p. 260-263), similar to props used in Spears' "Baby One More Time" and Knight's "Give It to You."

In the A\&F Quarterly, old microphones seem to be the preferred way to perform live music. This can been seen in a Harlem club in the Back-to-School 2000 edition (A\&F Quarterly, 2000c., p. 195) and in a New Orleans jazz club (2002a, pp. 69107). Similar microphones made appearances in Backstreet Boys "As Long as You Love Me," Hewitt's "How Do I Deal," 'N Sync's “Tearing Up My Heart.”

Surfboards were used throughout the A\&F Quarterly (1999a, pp. 65-75, 248; 2000a pp. 174, 204-5, 209; 2000b pp. 21, Back Cover). Meanwhile, surfboards made an appearance in Backstreet Boys "As Long as You Love Me," where a band member uses it as a photoshoot prop, and in Hoku's "Another Dumb Blonde" where a classic car rolls up with the surfboards on top of the car.

Many of these props work hand-andhand with the settings they appear in. Surfboards, for example, make sense in a beach setting, as in Hoku's "Another Dumb Blonde" and in many photoshoots for the $A \& F$ Quarterly. However, the reliance on beach scenes is greater than a few videos. Videos that featured beach scenes include, LFO's “Summer Girls," 98 Degrees' "I Do" and "Give Me Just One Night (Una Noche)," Aguilera's "Genie in a Bottle," and Spears' "Sometimes." Spears' "Don't Let Me Be the Last to Know" seems like the closest replica to A\&F Quarterly, as Spears and her love interest in the video embrace on a secluded beach. The love interest is topless for the entire while Spears is wearing and jean shorts. The scenery, howev- er, features beach huts with palm roofs, recalling various photo spreads in $A \& F$ Quarterly's Spring Break 1999 (pp. 135, 196) and the Summer 2002 issue, which featured similar amounts of dried palm and nudity as Spears' video (A\&F Quarter$l y, 2002 b$, pp. 2-36).

Two other examples can be seen in a carnival setting and in the city of New York. First, in Knight's "Give It to You," the action takes place at a carnival in a callback to the film Grease. Knight's singing and the group dancing takes place directly in from of the Ferris wheel, while other activities can be seen throughout the carnival. In a similar example, A\&F Quarterly featured a photospread in the Summer 2000 edition (2000b, pp. 74-92), prominently featuring a Ferris wheel as well as activities, such as carnival games.

Finally, New York is a frequent setting for artistic works, the A\&F Quarterly dedicated an entire issue to the city (1999c). While some music videos touched on New York, including 'N Sync's "Merry Christmas, Happy Holidays," it is worth remembering that $T R L$ broadcast from a prominent studio overlooking Times Square, where fans would gather daily. Like the entire issue dedicated by Abercrombie \& Fitch, the fact that TRL was prominently set in New York City, helping to unite the magalog life, the television show and the music videos.

\section{Discussion and future research}

The interplay between fashion brands and music videos remains a difficult terrain as neither offer clear narrative structures and their storytelling and meaning creation remains fragmented and contested. There are few clear, direct links between a music video and any specific brand and, as such, textual analyses must be malleable to order to find the links. The above pages offer three different modes of analysis to better understand the transfer of aesthetics between Abercrombie \& Fitch's marketing and popular music videos. The first analysis of the "Summer Girls" video explored how a direct call out by a song works to 
link the brand and the video aesthetics. The linkage between "Summer Girls" and Abercrombie \& Fitch was notable, but also relatively unique as there are few other examples of fashion brands getting a direct call out within a song. The second analysis looked at specific music videos to explore how the self-contained videos replicated the aesthetics of Abercrombie \& Fitch through its costumes and other elements. Notably, these videos replicated not only the Abercrombie \& Fitch advertising milieu, but also the aesthetics found in "Summer Girls.” The final analysis linked specific elements, such as costumes, props and settings, across music videos to show the extent of the repetition.

As with all historical analyses, the above analysis offers a specific cultural linkage for these specific elements. These findings cannot be extended to any general population and any extension of this research needs to be undertaken with its own careful analysis. That said, the above research offers some starting points for future research.

First and foremost, this research suggests that cultural ideas and aesthetics get reproduced and used across the spectrum of mediated popular culture. Specifically, the above pages examined how a the Abercrombie \& Fitch brand aesthetic was reproduced within music videos, but this could also be seen in other visual realms, including popular films and television of the time. Future research directions could either continue to interrogate the replication of Abercrombie \& Fitch's brand aesthetics, or interrogate if and how other fashion brands have navigated this relationship.

A second vein of research could follow how music videos contribute to the fashion zeitgeist at any particular point. The above showed repeated aesthetics in the videos that aired on MTV's TRL between 1998 and 2001, but suggests that on other shows might have similar intertextual references. This goes for other shows on MTV, but also shows from other music channels - i.e. CMT or BET - and in other cultural contexts.
Finally, future research could pursue how particular props, costumes and other elements get picked up and reused throughout the popular culture landscape. While the above specifically flowed from a fashion brand, it is assumed that the advertising is not the only contributor and the aesthetics, costumes and props offered up in music videos could easily be adopted by the advertising world, as well. Moreover, a question remains as to whether the fashion brand's aesthetic came first or whether it latched onto an existing trend.

\section{Conclusion}

This paper examined how the brand aesthetics of Abercrombie \& Fitch could be seen through popular music videos between 1998 and 2001. The fact that the brand's marketing images could have been ripped from popular music videos (and vice versa) helped drive Abercrombie \& Fitch's cultural influence and financial success and speaks to a notable symbiotic relationship between fashion branding and mediated popular culture. However, there is still ample work to be done. Acknowledging the influence of fashion aesthetics within music videos calls for a re-examination of the past productions and provides a different critical lens to discuss contemporary and future works.

\section{References}

Arnold, G., Cookney, D., Fairclough, K., \& Goddard, M. (2017). The persistence of the music video form from MTV to Twenty-First-Century social media. In G. Arnold, D. Cookney, K. Fairclough, \& M. Goddard (Eds.), Music/Video: Histories, Aesthetics, Media (pp. 1-13). New York: Bloomsbury.

Aurfderheid, P. (1986). Music Videos: The look of the sound. Journal of Communication, 36(1), 57-78. doi:10.1111/j.1460-2466.1986.tb03039.x

Benjamin, J., Johnston, M. Murray, N., Spanos, B., Stevens, K.. \& Walters, B. (2015, September 24). Greatest boy band songs of 
all time. Rolling Stone. Retrieved from http://www.rollingstone.com/music/ lists/50-greatest-boy-band-songs-of-alltime-20150924

Berfield, S. \& Rupp, L. (2015, January 22). The aging of Abercrombie \& Fitch. BloombergBusinessweek. Retrieved from http://www.bloomberg.com/news/features/2015-01-22/the-aging-of-abercrombie-fitch-i58ltcqx

Billboard Staff (2014, May 22). Top 30 summer songs. Billboard. Retrieved from http:// www.billboard.com/articles/list/513566/ top-30-summer-songs

Bruzzi, S. \& Church Gibson, P. (2004). "Fashion is the fifth character": Fashion, costume and character in Sex and the City. In K. Akass, \& J. McCabe (Eds.), Reading Sex and the City (pp. 115-129). New York: I.B. Tauris.

Coates, N. (2007). Elvis from the waist up and other myths: 1950s music television and the gendering of rock discourse. In R. Beebe \& J. Middleton (Eds.), Medium Cool: Music videos from soundies to cellphones (pp. 226-251). Durham, N.C.: Duke University Press.

Cookney, D. (2017). Vimeo killed the video star: Burial and the user-generated music video. In G. Arnold, D. Cookney, K. Fairclough \& M. Goddard (Eds.), Music/Video: Histories, Aesthetics, Media (pp. 255-267). New York: Bloomsbury.

De Cuir, G. (2017). 'The Message' is the medium: Aesthetics, ideology, and the hip hop music video. In G. Arnold, D. Cookney, K. Fairclough \& M. Goddard (Eds.), Music/video: Histories, aesthetics, media (pp. 53 -65). New York: Bloomsbury.

Denizet-Lewis, B. (January 24, 2006). The man behind Abercrombie \& Fitch. Salon. Retrieved from http://www.salon. com/2006/01/24/jeffries/

Dickinson, K. (2007). Music video and synaethetic possibility. In R. Beebe \& J. Middleton (Eds.), Medium Cool: Music Videos from Soundies to Cellphones (pp. 13-29). Durham, N.C.: Duke University Press.

Dretzin, R. \& Goodman, B. (February 27, 2001). The Merchants of Cool. Frontline. In B. Goodman (Producer) Boston, MA: WGBH.

Edmond, M. (2010). Fashionable attractions: Fashion parades in popular entertainment from Lady Duff-Gordon to Lady Gaga. Scan. Retrieved from http://scan.net.au/ scan/journal/display.php?journal_id=150

Fiske, J. (2011). Understanding popular culture $\left(2^{\text {nd }}\right.$ ed.). New York: Routledge.

Frith, S., Goodwin, A. \& Grossberg, L. (Eds.) (1993). Sound and vision: The music video reader. New York: Routledge.

Gaines, J.M. (2000). On wearing the film Madam Satan (1930). In S. Bruzzi \& P. Church Gibson (Eds.), Fashion cultures: Theories, explorations and analysis (pp. 159-177). New York: Routledge.

Goldstein, L. (1999, December 20). The alpha teenager. Fortune. Retrieved from http:// archive.fortune.com/magazines/fortune/ fortune_archive/1999/12/20/270530/ index.htm

Halligan, B. (2017). Liquidities for the Essex man: The monetarist eroticism of British yacht pop. In G. Arnold, D. Cookney, K. Fairclough \& M. Goddard (Eds.), $M u$ sic/video: Histories, aesthetics, media (pp. 97 -108). New York: Bloomsbury. Hancock, J. (2009a). Brand/story: Ralph, Vera, Johnny, Billy, and other adventures in fashion branding. New York: Fairchild.

Hancock, J. (2009b). Chelsea on $5^{\text {th }}$ Avenue: Hypermasculinity and gay clone culture in the retail brand practices of Abercrombie \& Fitch. Fashion Practice, 1(1), 63-85. doi:10.2752/175693809X418702

Heller, K. (2000, August 27). The man who would be... Dick Clark. The Philadelphia Inquirer, pp. I01.

Herzog, A. (2007). Illustrating music: The impossible embodiments of the jukebox film. In R. Beebe \& J. Middleton (Eds.), Medium cool: Music videos from Soundies to cellphones (pp. 30-58). Durham, N. C.: Duke University Press.

Holt, D.B. (2004). How brands become icons: The principles of cultural branding. Cambridge, MA: Harvard Business School Press.

Kooijman, J. (2017). The boxed aesthetic and metanarratives of stardom: Analysing music videos on DVD compilations. In G. Arnold, D. Cookney, K. Fairclough \& M. Goddard (Eds.), Music/video: Histories, aesthetics, media (pp. 231-243). New York: Bloomsbury. 
La Monica, P.R. (2016, August 30). Summer girls no longer shop at Abercrombie \& Fitch. CNNMoney. Retrieved from https://money.cnn.com/2016/08/30/investing/abercrombie-fitch-hollister-sales-earnings/ index.html

Lewis, L.A. (1993). Being discovered: The emergence of female address on MTV. In S. Frith, A. Goodwin \& L. Grossberg (Eds.) Sound and vision: The music video Reader (pp. 129-151). New York: Routledge.

Liptak, A. (June 1, 2015). Muslim woman denied job over head scarf wins in Supreme Court. The New York Times. Retrieved from http://www.nytimes.com/2015/06/02/us/ supreme-court-rules-in-samantha-elaufabercrombie-fitch-case.html

McBride, D.A. (2005). Why I hate Abercrombie \& Fitch: Essays on race and sexuality. New York: New York University Press.

Manghani, S. (2017). The pleasures of (music) video. In G. Arnold, D. Cookney, K. Fairclough \& M. Goddard (Eds.), Music/video: Histories, aesthetics, media (pp. 21-40). New York: Bloomsbury.

Mercer, K. (1993). Monster metaphors: Notes on Michael Jackson's Thriller. In S. Frith, A. Goodwin \& L. Grossberg (Eds.) Sound and vision: The music video Reader (pp. 193 -108). New York: Routledge.

Middleton. J. \& Beebe, R. (2007). Introduction. In R. Beebe \& J. Middleton (Eds.), Medium cool: Music videos from Soundies to cellphones (pp. 1-12). Durham, N.C.: Duke University Press.

Miller, J. (2011). Fashion and music. New York: Berg.

Munich, A. (2011). Fashion in film. Bloomington, IN: Indiana University Press.

The New York Times. (January 16, 1988). Abercrombie chain bought. Retrieved from http://www.nytimes.com/1988/01/16/ business/company-news-abercrombie-chain-bought.html

Perman, S. (2000, February 14). Abercrombie's beefcake brigade. Time, Retrieved from, http://content.time.com/time/magazine/ article/0,9171,996083,00.html

Railton, D. \& Watson, P. (2011). Music video and the politics of representation. Edinburgh: Edinburgh University Press.

Rich, M. (2008). Music videos: Media of the youth, by the youth, for the youth. In.
P.E. Jamieson \& D. Romer (Eds.), The changing portrayal of adolescents in the media since 1950 (pp. 78-102). New York: Oxford University Press.

Saviolo, S. \& Marazza, A. (2013). Lifestyle brands: A guide to aspirational marketing. New York: Palgrave Macmillan.

Sisario, B. (2008, November 18). Totally Over: Last Squeals for 'TRL.' The New York Times, pp. C1.

Spera, K. (2016, November 16). Christmas has been very good to a cappella quintet Pentatonix. The New Orleans Advocate. Retrieved from http://www.theadvocate. com/new_orleans/entertainment_life/ keith_spera/article_54366056-aa22-11e6a73d-97c7091f8c30.html

Straw, W. (1993). Popular music and post-modernism in the 1980s. In S. Frith, A. Goodwin \& L. Grossberg (Eds.) Sound and Vision: The Music Video Reader (pp. 1-21). New York: Routledge.

Uhlirova, M. (2013). The fashion film effect. In D. Bartlett, S. Cole, \& A. Rocamora (Eds.), Fashion Media: Past and Present (pp. 118 -129). New York: Bloomsbury. Vernallis, C. (2004). Experiencing music video: Aesthetics and cultural context. New York: Columbia University Press.

Walser, R. (1993). Forging masculinity: Heavy-metal sounds and images of gender. In S. Frith, A. Goodwin, \& L. Grossberg (Eds.), Sound and vision: The music video reader (pp. 153-181). New York: Routledge.

Warner, H. (2014). Fashion on television: Identity and celebrity culture. New York: Bloomsbury.

\section{Music videos}

Martel, D. (Director). (1999). Genie in a bottle. [Music video]. United States: RCA. Retrieved from https://www.youtube.com/ watch?v=kIDWgqDBNXA

Martin, L.C. (Director). (1998). Merry Christmas, Happy Holidays. [Music video]. United States: RCA. Retrieved from https://www.youtube.com/watch?v=wKj92352UAE

Raboy, M. (Director). (1999). Summer girls. [Music video]. United States: Arista. Re- 
trieved from https://www.youtube.com/ watch?v=6c60WPIRPQU

\section{Marketing materials}

Abadsidis, S. (1999, Spring Break). Young at Heart. A\&F Quarterly: Spring Fever, pp. 88-95.

A\&F Quarterly. (1998a, Back to School). On the Road. Abercrombie \& Fitch.

A\&F Quarterly. (1998b, Christmas). Ring It In. Abercrombie \& Fitch.

A\&F Quarterly. (1999a, Spring Break). Spring Fever. Abercrombie \& Fitch.

A\&F Quarterly. (1999b, Summer). Sumer Dreams. Abercrombie \& Fitch.

A\&F Quarterly. (1999c, Back to School). New York. Abercrombie \& Fitch.

A\&F Quarterly. (2000a, Spring Break). Wild \& Willing. Abercrombie \& Fitch

A\&F Quarterly. (2000b, Summer). Go Play. Abercrombie \& Fitch.

A\&F Quarterly. (2000c, Back to School). New York. Abercrombie \& Fitch.

A\&F Quarterly. (2000d, Christmas). A Very Emerson Christmas. Abercrombie \& Fitch.

A\&F Quarterly. (2002a, Spring Break). About Love ... Abercrombie \& Fitch.

A\&F Quarterly. (2002b, Summer). Paradise Found. Abercrombie \& Fitch

Bixby, G. (1999, Spring Break). Beachcombing. A\&F Quarterly: Spring Fever, p. 81.

Branch, A. (1999, Spring Break). Baja Nights. A\&F Quarterly: Spring Fever, pp. 138-145.

Carone, P. (1999, Summer). Fit to be Thaid. $A \& F$ Quarterly: Summer Dreams, pp. 60-63.

Gillies, J. (1999, Spring Break). Sands of Time. A\&F Quarterly: Spring Fever, pp. 252-253.

Kon, G. (1999, Summer). Poll Sharks. $A \& F$ Quarterly: Summer Dreams, pp. 159. christina-aguilera/chart-history/hot-100/ song/63926

"Genie in a Bottle," Christina Aguilera. (n. d.). In Billboard Chart History. Retrieved from https://www.billboard.com/music/christina-aguilera/chart-history/billboard-200/ song/ 174147

Home for Christmas, 'N Sync. (n. d.). in Billboard Chart History. Retrieved from https://www.billboard.com/ music/n-sync/chart-history/billboard-200/song/172038

LFO, LFO. (n.d.). In Billboard Chart History. Retrieved from https://www.billboard. com/music/lfo/chart-history/top-albumsales/song/174153

"Summer Girls," LFO. (n. d.). In Billboard Chart History. Retrieved from https://www.billboard.com/music/lfo/chart-history/hot$100 /$ song $/ 64130$

MTV. (n.d.) “MTV Timeline.” Retrieved from https://web.archive.org/ web/20160206065830/http://thepub. viacom.com/sites/mtvpress/Shows/ mtv-timeline

\section{Websites}

atrl. (n. d.). The TLR Archive. ATRL

Classic. https://web.archive.org/ web/20170613234811/https://classic.atrl. net/trlarchive/

Christina Aguilera, Christina Aguilera. (n. d.). In Billboard Chart History. Retrieved from https://www.billboard.com/music/ 
